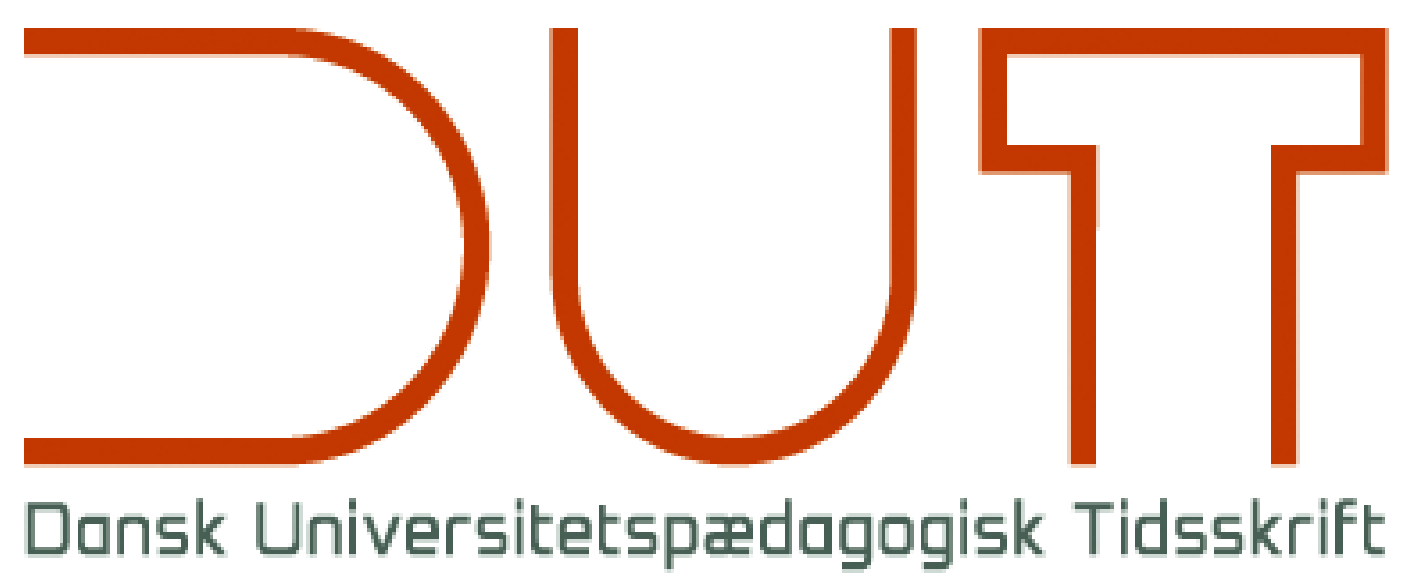

Læringsrum

Årgang 14 nr. 27 / 2019

Titel

Designing Hybrid Learning Spaces in Higher Education

Forfattere

Charlotta Hilli, Rikke Toft Nørgård, Janus Holst Aaen

Sidetal

$66-82$

Udgivet af

Dansk Universitetspædagogisk Netværk, DUN

URL

> http://dun-net.dk/

Betingelser for brug af denne artikel

(C) Copyright
Denne artikel er omfattet af ophavsretsloven, og der må citeres fra den. Følgende betingelser skal dog være opfyldt:

- Citatet skal være i overensstemmelse med "god skik"

- Der må kun citeres „i det omfang, som betinges af formålet“

- Ophavsmanden til teksten skal krediteres, og kilden skal angives ift. ovenstående bibliografiske oplysninger.

DUT og artiklens forfatter 


\title{
Designing Hybrid Learning Spaces in Higher Education
}

\author{
Charlotta Hillia,1, Rikke Toft Nørgård ${ }^{\mathrm{b}}$, Janus Holst Aaen ${ }^{\mathrm{b}}$ \\ aFaculty of Education and Welfare Studies, Åbo Akademi University, ${ }^{\mathrm{b}}$ Centre for Teaching Development \\ and Digital Media, Aarhus University
}

Research article, peer-reviewed

\begin{abstract}
As Hybrid Learning Spaces move beyond distinctions between online and offline spaces, they challenge divisions between teacher/student roles, formal/informal contexts and analogue/digital communication and media. This article presents the concept of hybridity in higher education through a concrete example of a transnational hybrid course collaboration between three teachers and thirty students at Aarhus University, Denmark and Åbo Akademi University, Finland. The course design is examined through theories on hybrid pedagogy, learning spaces and media ecology to suggest five design principles for Hybrid Learning Spaces. The paper argues that higher education has the potential of inviting students to learn in the world, with the world and for the world, in a way that cuts across traditional dichotomies and barriers.
\end{abstract}

\section{Introduction}

The design of learning spaces impacts and shapes the learning activities taking place and encourages new educational activities (Bligh \& Pearshouse, 2011). There are many instances of innovative practices in higher education which challenge traditional conceptions of learning spaces (e.g., Nørgård, Mor \& Bengtsen 2019; Canals, Burkle \& Nørgård, 2018; Nørgård \& Bengtsen, 2016; Garrison \& Vaughan, 2008). But a need remains to theoretically underpin such innovations to develop pedagogy and design principles to aid in their practical implementation in higher education on a larger scale, in a way that moves beyond secluded islands of creativity scattered across institutions of higher education (Goodyear \& Yang, 2009; Kali, Levin-Peled \& Dori, 2009). Following this development, a need has arisen to reevaluate the nature of the learning space in an educational context. Over the years, the confines of the physical classroom have been challenged and a broader notion of learning spaces has emerged, indicating that learning can no longer be perceived as tied to brick and mortar (Temple, 2008). For more than a decade, the classroom has also existed in digital and online formats. However, learning spaces in the form of digital or online classrooms are still to a large degree conceptualized as exactly that: physical learning spaces going online or becoming digital.

In this article, we investigate the potential of reconceptualizing learning spaces through the notion of hybridity to consider ways of creating new classroom experiences that cut across countries, courses, roles, contexts, as well as communication and media platforms. We do this theoretically by including theories on hybridity and hybrid pedagogy to empirically describe and examine a course we designed and implemented for Hybrid Learning Spaces in Spring 2019. On the basis of this understanding, the article proposes five design principles for Hybrid Learning Spaces in higher education. The overall research question that the article

${ }^{1}$ Contact: chilli@abo.fi 
pursues is this: What are the characteristics of Hybrid Learning Spaces and their pedagogy and what are some general design principles for developing Hybrid Learning Spaces?

Hybridity, as it is described in this article, is based on the research on hybridity in general and hybrid pedagogy in particular. Hybridity is not to be confused with other uses of digital media to support learning such as flipped classroom or blended learning. The concept of Hybrid Learning Spaces is different from flipped classroom as it is not an instructional strategy that reverses the traditional learning environment and moves instructional content outside the classroom and activities that traditionally take place outside the classroom into the classroom. Likewise, hybridity is not to be confused with blended learning that uses sequences of online and offline learning activities and combines online materials with in-person instructions. Finally, even though Hybrid Learning Spaces and hybrid pedagogy share some affinity with other fields such as computer supported collaborative learning, distance learning, e-learning or networked learning, we hope to show that it is also a field in its own right. As such, the term hybridity stresses the mixture and fusion of traditionally separate parts to create a new hybrid that is not a blend or something flipped, but something in its own right, something different.

Following this, a Hybrid Learning Space is a context of learning that not only moves beyond distinctions between online and offline spaces, but also often challenges divisions between teacher/student roles, formal/informal contexts, analogue/digital communication/media and other traditionally separable dimensions. Hybrid Learning Spaces and hybrid pedagogy offer new 'complex hybrid breeds' and as such potentially new possibilities for collaboration in higher education.

The Hybrid Learning Space described in the article emerged through a course collaboration between Aarhus University, Denmark and Åbo Akademi University, Finland. Established in Fall 2018, the aim of the collaboration was for the students and teachers from Denmark and Finland to meet online together in a joint course track, cutting across the MA courses "Design: theory, method and practice" (ICT-Based Educational Design, Aarhus University) and "Pedagogical Perspectives on Digitization" (General and Adult Education, Åbo Akademi University). The joint course track was to constitute half of the teaching carried out in the two courses, while the other half was to be taught individually by the teachers on the two respective courses. Pedagogically, the content, the learning goals, the learning environment and the teaching and learning methods of the courses were interlinked to transform the routines of learning (Harrison, 2018). The pedagogy, learning space and media ecology were chosen and set up to support and promote the course design and aims of the transnational, interlinked courses and groups of students. Together, the pedagogical and technological design constituted an instantiation of 'Global Online Inter-university Teaching' (GO: IT - also described in Nørgård, Mor \& Bengtsen, 2019; Bengtsen \& Nørgård, 2018) a learning space for hybrid higher education and networked learning.

Hybrid learning suggests blurred boundaries between teacher and students; it is open to collaborative learning where student agency is important for the collective efforts of students to be beneficial. Digital spaces can support collaborative learning among students and foster a sense of community and shared knowledge (Harasim, 2012). Computer supported collaborative learning $(\mathrm{CSCL})$ usually combines digital and physical spaces while students collaborate and has become an established approach in most classroom practices where student collaboration and digital learning spaces are concerned Jeong, Hmelo-Silver \& Yu, 
2014). In Hybrid Learning Spaces, contexts, roles, media and sometimes even curricula and countries are mixed and fused in new ways.

The case presented in the article was a transformation of two partially online courses at two different higher education institutions in two different countries with two different curricula and learning outcomes, taken by students with different backgrounds and coming from different disciplines and using different learning management systems that did not integrate. The courses are instantiations of distance education and online learning; students are introduced to models and methods of digital learning environments, online social interactions, and learning to support students' digital competence to navigate the spaces used, furthermore, they are encouraged to take part in activities in the online community (Salmon, 2011). According to Michael G. Moore (2013), a less structured course with more student autonomy can be argued for if dialogues between teachers and students or students and students are foregrounded and frequent. This was the case, as the course was structured around hybrid pedagogy (see below) in the form of critical dialogicality aimed at transforming roles and context to create a hybrid learning environment, a 'teaching-based research collective' (Nørgård \& Mathiesen, 2018; Aaen \& Nørgård, 2015) where students and teachers alike were positioned as research partners around the shared theme of 'digital change in education'. Overall, the student hybrid collaboration across countries, curricula, courses, and contexts were executed across platforms and projects further confirming the need for theories on hybridity and hybrid pedagogy to create a genuine fusion of these different dimensions.

Before going deeper into the case, however, the theoretical framework underpinning the Hybrid Learning Space in the form of hybrid pedagogy, learning spaces and media ecology is presented. Second, the case, 'GO: IT - Digital Change in Education', and its Hybrid Learning Space are introduced. Finally, the design principles for and implications of Hybrid Learning Spaces are put forward and discussed based on the theories and case presented.

\section{Dimensions of hybridity and hybrid pedagogy}

As a term, hybridity originates from Latin and has its roots in biology where it refers to cross-fertilization or the fusion of separate parts or species into a new one. But it has also been used to describe 'hybridized cultures' such as that of the Romans and the way they adopted and remixed elements from other cultures into their own. As such, hybridity denotes something other or new that occupies at least two places at once (Bhabha, 1994). Building on Bakhtin (1984), hybridity can be described as polyphonic, and in this way hybrid education becomes multifarious and heterogeneous in nature. Consequently, hybridity is not 'safe' or 'familiar', but always on the move towards something new, never fully formed or determined (Rorabaugh \& Stommel, 2012).

Through the concept of hybridity, educational developers and scholars work to dissolve the dichotomies between, for instance, offline/online, digital/analogue or formal/informal that currently exist in higher education. According to Jesse Stommel (2012), one of the founders and editors of the journal Hybrid Pedagogy, the 'hybrid' of hybrid pedagogy focuses on new configurations of and connections between dimensions such as:

- $\quad$ Physical learning space/digital learning space

- $\quad$ Analogue/digital materials and technologies 
- Informal/formal learning contexts

- $\quad$ Onground classroom/online classroom

- $\quad$ Academic product/learning process

- Disciplinarity/interdisciplinarity

- Individual teachers, students, scholars, citizens/collaborative communities

- Learning at the university/learning in the world

- Use of tools/critical engagement with tools

- Dissemination of knowledge/experiential learning

In hybrid acts of teaching and learning, the institution, space, teachers, scholars, students, citizens, employees, tools, contexts etcetera enter into close dialogue and partnerships with each other. In doing so, the dimensions are allowing themselves to network and be networked. Hybrid pedagogy merges the dimensions to such an extent that they become part of the same ecological system. These interconnections have caused Barnett (2018) to call this form of higher education institution 'the ecological university'. A Hybrid Learning Space, then, is one particular configuration of ecological higher education. Hence, hybridity in higher education is realized through educational formats, activities and acts that acknowledge "otherness and difference as something productive and of in-between spaces [...] As such, hybrid education is characterized by open-endedness, risk-taking, experimentation, empathy, dialogue and critical creativity" (Köppe, Nørgård \& Pedersen, 2018, p. 5).

In hybrid higher education, the above dimensions open up teaching and learning to society and the world through allowing an entanglement with networks, spaces, processes, collectives and ecologies, enabling students and teachers to think, talk and tinker with the things, people and communities they encounter there. The creation of a Hybrid Learning Space requires mutual commitment, care, respect and collaboration between the parties and dimensions entering into hybrid connectivity in an effort to co-create a shared world (Barnett, 2011; Aaen \& Nørgård, 2016; Nørgård, Mor \& Bengtsen, 2019).

At its core, hybridity refers to a mixture of different parts into a new breed, form or culture (e.g. mules, grapefruits or Bollywood). Hybrid forms and cultures, such as Hybrid Learning Spaces or Global Online Inter-university Teaching, involve the intentional and reflective fusing of different elements from the dimensions above. Accordingly, hybridity in higher education implies a pedagogical design that mixes different discourses, formats, tools, people, contexts etcetera; a design that aims to invigorate higher education teaching and learning itself by creating new hybrid interactions and experiences. Rorabaugh and Stommel (2012) directly address hybridity in education and point towards hybridity as a way to keep higher education open to the world and to itself:

As a philosophical concept, hybridity suggests hesitation at a threshold. Hybridity is not an attempt to neatly bridge the gap, but extends the moment of hesitation and thereby confuses easy categorization. And, as we allow the things to rub against each other, two things that might not otherwise touch, we invite them to interact, allowing synthesis (and even perforation) along their boundaries. As the digital and analogue - the physical and virtual - commingle, we must open to random acts of pedagogy - to connections that are, like the web, associative and lively but sometimes violent and deformed. In this hybridity is 
not always safe, moving incessantly (and dangerously) towards something new - something yet undetermined (Rorabaugh \& Stommel, 2012, unpaginated)

It is against the backdrop of the above understanding of 'hybridity' that we have created a Hybrid Learning Space using the format of Global Inter-university Teaching (GO: IT) to let people inside and outside the singular institution intermingle through joint dialogues, cocreated products, shared processes and collective projects (see the case below for a description of the GO: IT format). As students within the singular institution or classroom enter into dialogue, collaboration and co-creation with teachers, other students, citizens or scholars, the possibility for other forms of teaching, learning, scholarship and academic practice emerges and comes to the fore. In the case described in this article, the concept of Hybrid Learning Space is presented in more detail through the format of Global Online Interuniversity Teaching, which is one design pattern for hybridity in education among many $(\approx 90)$ developed at the 4-day workshop, EduPLoP16: Hybrid Pedagogy, organized by one of the authors and with the participation of around 10 educational developers and researchers.

Overall, our prior work on hybrid education and hybrid pedagogy (Köppe, Kohls, Pedersen, Nørgård \& Inventado, 2018; Pedersen; Nørgård \& Köppe, 2018; Köppe, Nørgård \& Pedersen, 2018; Kohls, Nørgård \& Warburton, 2017) highlights a shift in the structure of higher education, as well as in teaching and learning towards hybrid connectivity, networks and collaborations through joint engagements in hybrid research processes with each other and with society. Hybrid Learning Spaces cut across, transform or even transgress traditional boundaries and dichotomies; through such transformations and transgressions, hybrid education asks of us - as teachers, students, scholars, citizens - to reflect on the reasons for, value and purpose of upholding these dividing lines: "In hybrid education people inside and outside the campus [or learning space] meet and intermingle, academic life, becomes mongrel as the personal, professional and academic merge. Even teacher, students and institutions crossfertilize to construct new hybrid contexts and collectives across traditional boundaries [...] On the grounds of such different hybrid constellations, the possibility for new higher education futures emerges" (Köppe, Nørgård \& Pedersen, 2017, p. 2).

\section{Digital learning spaces}

Space is studied from different perspectives; geographical, psychological, anthropological, sociological among others. When it comes to learning in certain spaces more research is needed on what the concept entails from pedagogical perspectives. According to Harrison (2018), learning space as a concept is under-theorized (see also Bligh \& Pearshouse, 2011). Space sets boundaries for actions related to teaching and learning; the furniture and technology in the classroom can support certain strategies and constrain what teachers and students want to do. Digital learning spaces include online and offline platforms, social media, virtual games, virtual worlds and other kinds of spaces students and teachers learn and teach in. Furthermore, space is embedded with meaning as it is relational and filled with objects that people find important or meaningful. This is something we will discuss in the next section on media ecology.

Digital learning spaces can challenge power structures in education by making it possible for students to search for information on their own and question the content presented by the teacher (Livingstone, 2012). At the same time, researchers and teachers need to be mindful about the implications for social relations and learning that follow with new learning spaces. Oliver (2015, p. 366) highlights the importance of critical reflection on who might be excluded 
or closed-off through digital spaces. Digital spaces are no more neutral than classrooms, and digital issues of privacy and data protection need to be considered when venturing out into spaces that are upheld and owned by private companies such as Google and Facebook. Goodyear and Carvalho (2014) point out that the uneven distribution of access to Internet creates inequality among people - although a similar critique can be addressed to previous media like printed books.

From a faculty point of view, digital learning spaces generally include learning management systems (LMS) and email providers (Bates, 2005). Research confirms that private devices (e.g., smartphones, laptops) and personalized spaces (e.g., social media) compliment the equipment and platforms offered by the higher education institutions. There is a space-time aspect that is necessary to address in digital spaces. The perception of time changes in online or distance education. Melhuish (2018, p. 19) sees digital learners as living complex lives requiring time-management skills as boundaries between learning and other everyday activities fade. Information is available round the clock and communication patterns may change if students stay in touch with each other anytime and anyplace. As space and culture are intertwined, the pace for learning is changing in the digital age. While fast internet connections and immediate access to information benefit many learners, it may also lead to a sense of disorientation and uncertainty (Harrison, 2018).

Most learning theories have been established during the beginning of the 20th century providing psychological perspectives on learning, making the subject or the learner the focus of the study (Harasim, 2012; Goodyear \& Carvalho, 2014). Pedagogical ideals of the 21st century, such as, lifelong learning, creativity, and flexibility are not represented in theories based on cognitive aspects of learning, nor are socio-material aspects of learning. Harasim (2012, pp. 79-108) suggests online collaborative learning emphasize constructing knowledge together rather than repeating knowledge individually. It requires active learning techniques to address problems and issues in the 21 st century, and knowledge is seen as a shared activity within a group of people. Harasim structures online collaborative learning in three steps (p. 93); first, collaboratively generating ideas, second, collaboratively organizing ideas, third, ending with a shared understanding or agreeing to disagree, for example, by offering different solutions to a complex problem. This way, all students contribute to the shared project and reflect on the contributions by others to reach some form of synthesis. A sense of community is needed for students to actively contribute to the shared knowledge. Well-known issues with collaboration include unequal workloads and difficulties in communicating about group decisions; a course design and assessment methods based on collaborative learning principles are ways to avoid said issues (Macdonald, 2003). The learning space needs to support content creation by students and collaboration making all digital tools important parts of the shared learning space or the online community. The process and the product of learning are equally important in online collaborative learning while previous learning theories generally favor the product or the cognitive development.

Theories of networked learning are associated with new digital technologies. Keep in mind that people have been networking and learning in informal spaces throughout the history of humanity (Goodyear \& Carvalho, 2014). Networks of people, organizations or teams learning with and from each other require horizontal and vertical understandings of learning. Horizontal activities relate to different areas of a person's life and all communities the person interacts with. Vertical activities are more clearly related to one specific social system like a 
school. Akkerman and Van Eijck (2013) call it the hybridization of education and everyday life experiences when the whole person is considered, not only certain activities or tasks a person performs within a schooling system. Learning is mediated through written digital texts or other forms of communication; it means trusting people you do not meet face-toface. Theories of networked learning downplay the differences between digital and physical spaces as people live and act in both spaces.

As mentioned above, the dichotomy between physical and digital spaces is dissolved in hybrid pedagogy as human beings learn and network in both environments. The ideas of online communities, trustworthy networks for collaborative learning and horizontal processes are important in Hybrid Learning Spaces. Hybrid learning relies on collaboration and dialogue between networks of people and it is not the subjective view we are after, rather the collective efforts in a socio-material environment aiming at creating something new and shared.

\section{Hybrid Learning Spaces as media ecology}

In early studies of digital media, a tendency to confine inquiries into online sociality to singular media was established (e.g., Gotved, 1997; Rheingold, 1993). Communities were regarded as belonging to certain websites and movements between these sites were not an object of scrutiny. However, as more advanced online services and media were developed especially in the second half of the 2000s (Jensen \& Tække, 2018), a need arose to reevaluate how people engaged with online media. Baym (2007), in a study of music fandoms, found that communities were formed across an array of media rather than on singular sites. And, in a major study of young people and new media, Ito et al. (2010) found that rather than using this or that online platform for a given purpose, youths participated in a media ecology with and alongside their relations. A media ecology, then, is both individual and shared. It consists of a number of medias on different levels, including terminals (e.g., computer, mobile phone, radio, television), platforms (e.g., browsers, apps, operating systems) and services (e.g., WordPress, Facebook, Google Docs, Snapchat, Zoom). The participant in the media ecology engages with different parts of the ecology with the aim of pursuing different meaningful objectives - such as relation building, task solving, learning, having fun etcetera - but the relations she maintains or establishes through the media are often engaged through a multitude of channels rather than just one. As an example, students might engage in group work that involves a number of medias. They might write together in Google Docs, have a Facebook group for coordinating their work, go to Blackboard to download the course literature and have online meetings on Skype. Moreover, the individual student might have a range of media, that support his/her learning activities - what Dabbagh and Kitsantas (2012) and others have called Personal Learning Environments. These could for instance be applications that sort users' references (e.g., Zotero, Paperpile, Endnote), sites that students visit to find information (e.g., Reddit, Twitter, Wikipedia) or note-making applications (e.g., Evernote or OneNote). Students' media ecologies, then, are both shared and individual.

In a previous article, Aaen and Nørgård (2016) suggest that a media ecology may be deliberately established to support a given educational activity. Realizing that different types of ecologies might promote different educational values, it becomes important not only of which parts the ecology is comprised, but also how the students and teachers participate in it. Certain media might afford certain uses through their technical architecture, but the affordances will invite a range of uses - some of them realized, some of them not (Bucher \& 
Helmond, 2017). You could say, following Gibson's (2014) work on affordances and ecology, that a particular media ecology represents a certain ecological niche. Such a niche is created in the meeting of participants and media and is a way of living with media that emerges in a negotiation between the technical characteristics of the media and the particular people participating. Much as a giraffe has problems living on a steep mountain side but thrives under the acacia trees of the flat savannah, not all ways of participating are possible in a particular media ecology. On the other hand, the savannah as a particular landscape does not determine the existence of the giraffe. After all, similar habitats are found around the world where no giraffes exist. In the same manner, the existence of a given media ecology might make a certain pedagogy possible, but there is no guarantee for its emergence.

Because of this, pedagogical choices need to be made with regard to the kind of participation that may support the educational activities in a satisfactory manner. Hybrid pedagogy, as discussed above, entails a certain way of regarding educational activities. Transcending the dichotomies of teacher/student, physical space/virtual space, academic space/extraacademic space, this educational approach demands particular affordances of the ecology to be highlighted, while others should be repressed. For instance, video conferencing systems might be used to foster vibrant and non-hierarchical discussions of a subject but might as well be employed as a top-down platform used for teacher information-dumping onto students - representing two radically different niches for the students.

Media ecologies are hybrid phenomena in themselves. They transcend individuality and sociality, institutional services and private services and formal and informal contexts. As such, deliberately working with a critical development of media ecologies has the potential of realizing a hybrid pedagogy. On the other hand, the emergent and distributed nature of media ecologies defy complete control by teachers, allowing power to be democratized to an extent.

\section{GO: IT - A Hybrid Learning Space for 'Digital Change in Education'}

The case described below utilizes the hybrid education pattern 'Global Online Inter-university Teaching (GO: IT)' developed partly through collaboration, writing and co-teaching between Gwyneth Hughes at the Institute of Education, University College London and Rikke Toft Nørgård at Centre for Teaching Development and Digital Media, Aarhus University (Hughes \& Nørgård, 2017), partly through developing a pattern for it at the EduPLoP'16 workshop at Sandbjerg Gods. The GO: IT hybrid education pattern is described in Nørgård, Mor and Bengtsen (2019), but an account of the pattern is also given here for the comprehensibility of the case:

Global Online Inter-university Teaching (GO: IT): In inter-university teaching and learning, academics, researchers and teachers teach on each other's courses across different universities and/or courses by giving lectures and participating in each other's classrooms or courses through video conferencing or shared writing spaces. One benefit is that teachers get the opportunity to take advantage of their professional networks and invite research colleagues from around the globe into their classroom and think and talk together without having to pay the cost of transport and spend unnecessary time traveling. More than just experiencing expertise, students get the benefit of multiple perspectives and voices in their course, making it more connected, polyphonic and hybrid. Moreover, students might feel as a part of a global research community. It is, however, important that the teacher is the hub in inter-university teaching as the course otherwise runs the risk of becoming fragmented 
where 'the teacher of the week' just keeps dipping in and out without any coherence. Rather, the teacher needs to be the spider in the web, sensing and pulling the strings. Integrating inter-university teaching in the course with all its accompanying benefits therefore also means taking on the ethical responsibility for the collective co-located experience and the coherence of the course, spinning webs between sessions and across the curriculum (Nørgård, Mor \& Bengtsen, 2019).

The case presented here was a course collaboration between "Design: theory, method \& practice" (20 ECTS), part of the MA in ICT-Based Educational Design, Aarhus University, Denmark and "Pedagogical Perspectives on Digitization" in General and Adult Education, Åbo Akademi University (5 ECTS) from February to May 2019. The planning of the course took place in the fall of 2018. Both universities were offering courses related to educational design or digital learning which made the courses eligible for collaboration. The Hybrid Learning Space evolved around the use of Google Drive, Zoom and WordPress which supported student collaboration on an online book with the title Digital Change in Education. The two groups of students were equal in size and consisted of approximately 15 participants from each university. They were divided into three groups following the three topics of the course; hybrid pedagogy, value-sensitive design and learning spaces. Each of the authors of this paper was assigned one group to mentor according to research interest and to support the group during the course. Through prior experience and scholarship, the three teachers held the pedagogical and digital competences to execute the course (Bates, 2005; Harasim, 2012). The language chosen by the students was English, although they could use Danish or Swedish respectively to communicate with each other and in their texts. Danish or English are the official languages for "Design: theory, method \& practice". Swedish or English are the official languages for "Pedagogical Perspectives on Digitization". By choosing English the students and teachers also decided that the resulting open WordPress book and concluding open Zoom webinar were aimed at an international audience interested in new knowledge and emerging trends within digital education. This added yet another layer of hybridity to the learning space as local (Aarhus University \& Åbo Akademi University), national (Denmark \& Finland) and global contexts were collapsed in the book and webinar into a 'glocal' course with decidedly outward-looking products.

The five design principles presented in the last section of the article were deduced from theories and concepts from hybridity and hybrid pedagogy and the design and practice of the GO:IT Hybrid Learning Space described in the following. As such, the design principles fuse theory and practice into principles for conceptualizing, promoting and implementing Hybrid Learning Spaces in higher education. Combined, the design principles exemplify the dissolution of the dichotomies offline/online, digital/analogue, teacher/student, highlighting what the different hybrid parts of the course added to the learning space and experience. The Hybrid Learning Space chosen correlated with the values and core traits of hybridity to foster empathy and dialogue among students through extensive and complex student and teacher collaboration in the digital spaces. This was in turn expected to introduce breadth and depth in the teacher-student and student-student collaboration making constant dialogues and joint decisions important to move the book project onwards and support the values previously described. Theories on media ecology related to creating an ecological niche where different devices, people, and tools are mixed in hybrid ways to create something new. This required a multifarious, polyphonic and rhizomatic approach where experimentation, fusion, and collaboration are encouraged in both learning processes, assign- 
ments and spaces. In the last section, these five design principles for hybridity: 1) rhizomatic places and knowledge forms, 2) dissolving dichotomies in education, 3) creating a niche in the environment, 4) breadth and depth of the collective and 5) value-sensitive spaces will be described more thoroughly. But first the case from which the design principles manifest themselves will be described more in depth.

\section{The Hybrid Learning Space}

The media ecology created required that students had access to own devices. They needed a strong internet connection as they were asked to have video turned on in the webinar sessions using the videoconferencing system Zoom so that they could see each other. All students had access to and used Google Suite for Education for collaboration, file handling, teacher feedback, sharing of recorded videos from the video-conference meet-ups as well as students' data, materials and resources. Google Suite for Education was used due to the fact that the Danish students had BlackBoard as their institutional Learning Management System (LMS) while the Finnish students had Moodle as their LMS. These two systems were closed off to each other and thus prevented the students and teachers to share materials freely and collaborate fluently between countries, contexts, and courses. The Google Suite for Education was chosen as it complies with the GDPR rules, have unlimited storage capacities and allow students the same rights as teachers in relation to communicating, sharing, collaborating, editing, creating and so forth. Overall, Google Suite for Education allowed for fluent integration of the two cohorts across these dimensions in effect creating a hybrid teaching-based research collective (Nørgård \& Mathiesen, 2018).

Besides the services offered by Google Suite for Education, Zoom was used for online teaching across institutions, group meetings, supervision and teacher planning. Furthermore, the WordPress blogging platform was chosen as the platform to deliver the final output of the course - a collaboratively written digital book - where the three groups consisting of both Danish and Finnish students transformed their internal group work on the Google Drive into external research contributions to a wider society through the WordPress platform. Overall, the extended hybrid media ecology aimed at creating a 'new breed' of learning environment through fusing curricula, learning spaces, learning contexts, classrooms, group work and processes, distinctive disciplines, teacher-student roles, on campus and off campus learning, as well as teaching and learning tools and resources in inherently hybrid ways. The students were able to access, manage, and co-create this Hybrid Learning Space through the use of the offered hybrid media ecology at any time which adheres to the ideas of mixing individual and shared spaces, media, and activities typical for a both hybrid pedagogy and media ecology as described above.

Five webinars were held during the Spring of 2019 on Zoom as it supports breakout rooms which let participants move into a space of their own to discuss topics in small groups. Each webinar meant introductions by the teachers and group discussions on course related topics. The webinars structured the hybrid course to create a sense of presence and intimacy within the groups. While synchronous forms of communication supported student collaboration, the course design, however, needed to include tasks to encourage students to interact. For them to own their niche, it was not enough to offer the software for it. The teachers needed to make conscious decisions to include collaboration in the course design to support student collaboration and students' trust in each other (Beldarrain, 2006; Macdonald, 2003; Wang, 
2009). The webinars helped to provide such a structure and offered participants the opportunity to ask questions and ask for support.

\section{Hybrid learning activities}

Research on hybrid pedagogy suggests using digital environments to collaboratively produce new knowledge while embedded in physical and digital spaces (Harrison, 2018; Stommel, 2012). In an attempt to realize this, the finished product was a co-authored online book. Even though the groups had different themes, all of the groups shared the common focus of 'Digital Change in Education'. The book was launched through a co-hosted webinar for everyone interested in the themes and focus. The teachers wrote the introductory and concluding discussions to highlight aims, goals and results of the book project. The outline of the book was adapted to a digital space to include pictures to make the reading more interactive.

The online book was divided into three parts that structured the course work in itself. The first part of the book serves as an introduction; the participants individually searched for literature on their assigned topics and annotated texts the other group members had found. The students individually wrote a short literature review that they later combined into a group text. As a group, they chose one text that the whole group would benefit from reading. The groups collaboratively wrote a manifesto of what digital change in education meant for them and in the context of their chosen topics.

The second part of the book includes theoretical inputs and ideas on Design-Based Research which was the methodology chosen. It offered the students the possibility to learn more about Design-Based Research as a group. Furthermore, Design-Based Research was connected to previous research, theories, and practice to suggest ways forward on digital change. The third part of the book consists of the prototypes that students developed to exemplify the topics of the book. The prototypes served as examples of feasible ways forward for digital change compared to the idealistic manifestos summarizing values on digital change. The students were supposed to plan and execute their prototypes in relation to the topics of the course; they were free to choose what they designed and where it took place according to their interests. The students collaborated with educational settings (e.g., surveys, interviews, workshops) and developed prototypes (e.g., apps, games) to solve certain problems in those settings, which further confirms the hybrid nature of the course and the connections between physical and digital spaces (Stommel, 2012).

The pedagogical aims addressed theoretical and practical issues of digital change in education. By extending the collaboration to another university, the possibilities and challenges of digital change were included in all aspects of the course design; the teaching methods, the assessment methods, the content and aim of the course. Online collaboration and networks were used to support learning and knowledge building processes among the students. The course participants followed the processes of the other groups (webinars, Google Drive) and peer-feedback was used on texts (Google Drive) prior to publication. The design process of the book related to the hybrid nature of the course. The students were actively involved in all stages of the book process empowering them to take control over the content, the process, the collaboration, and the direction of the course (Beldarrain, 2006;

${ }^{2}$ Link to the digital book Digital Change in Education: https://digitalchange.home.blog/ 
Livingstone, 2012). The teachers provided feedback on the chapters written by students as a way to support the students' understanding of the theories and the method Design-Based Research. The chapters were developed by the students and their joint understanding of the theories and method. In this way, media ecology, digital spaces, and hybrid pedagogy were combined to structure the course and bring on dynamic dialogues between the physical and digital spaces of the students (Stommel, 2012).

Pedagogically, we worked on practical, theoretical, and methodological levels to understand and develop knowledge about digital change. In the next section, the design principles for Hybrid Learning Spaces are presented on the basis of our practical experiences and on the theoretical underpinnings laid out in the previous sections.

\section{Design principles for Hybrid Learning Spaces}

Taken together, the above theory and practice - the concepts and case of the article - point towards five design principles that scaffold and promote Hybrid Learning Spaces as an intentional and reflective educational practice in higher education. Considering the concepts of 'hybridity', 'learning spaces' and 'media ecology', the educational pattern of 'Global Online Inter-university Teaching', as well as the case of 'GO: IT - A Hybrid Learning Space for Digital Change in Education', a particular sort of learning space is formed; it is not just any learning space, but a particular learning space based on particular theoretical frameworks, emerging from particular design principles and patterns, and materializing itself as a particular case - the Hybrid Learning Space.

Synthesizing all of the above, a set of five design principles for designing, developing, and implementing Hybrid Learning Spaces in higher education can be formulated:

1. Rhizomatic places and knowledge forms: In designing for Hybrid Learning Spaces the new hybrid needs to be a fusion of separate parts that keeps the learning and teaching in the space open-ended in ways that support and invite for rhizomatic, polyphonic, and heterogenous knowledge forms - and even random acts of teaching and learning - it is a learning space that emerges as 'vibrant matter' or learning that might intentionally 'hang in the balance'.

2. Dissolving dichotomies in education: The composition of a Hybrid Learning Space is simultaneously the decomposition of dichotomies - rather than thinking in exclusive ors, the hybrid learning designer thinks in inclusive ands. It is a learning space that tries to simultaneously be physical and digital, online and offline, process and product, for the individual and the collective, for the university and the world, formal and informal, synchronous and asynchronous and so forth. Hybrid Learning Spaces are the intentional and reflective dissolution of particular dichotomies based on particular pedagogical purposes aiming for particular learning interactions and experiences. It is a space of inclusion, not exclusion.

3. Creating a niche in the environment: The drawing together of a hybrid space for learning creates a media ecology given that a Hybrid Learning Space is not delimited to one configuration, system, platform or place, but forms across an array of elements, channels and layers. The space constitutes an 'ecological niche' where scholars, teachers, students, citizens, employers, contexts, media, materials, and so on connect in a certain way to create an 'invigorating and sustainable niche for learning and teaching' that is intimately integrated within and has a permeable membrane towards the surrounding ecological sys- 
tem. Creating a new Hybrid Learning Space is simultaneously the creation of a new ecological niche where new learning and life forms can take place.

4. Breadth and depth of the collective: A Hybrid Learning Space is made for and by people that breathe, live, and learn together. As such, it is a space with depth and breadth - a constellation of joint engagement in individuals, partnerships, teams, groups, collectives, communities and networks. It is people who, like burdocks, hang on to each other and the world through forming hybrids by fusing their personal learning environments with their group learning environment with their class learning environment with their collective cohort learning environment. In Hybrid Learning Spaces, depth emerges through breadth via the burdocks holding it all together as teachers and learners get together to work across media and platforms, touch base and share space, books, and projects in breakout rooms, in relation to demarcated tasks, and individual exam papers. It is a fusion through a constant flux of being together as a collective through joint teaching in webinars, being together as a group through joint writing in book chapters and being together as persons through individual writing of exam papers in the course.

5. Value-sensitive spaces: Finally, the creation of a Hybrid Learning Space is simultaneously the creation of a value-sensitive space. Hybridity and media ecologies carry with them certain virtues and values imbuing the learning space with an 'ethics of teaching and learning' characterized by open-endedness, risk-taking, experimentation, collaboration, dialogue, empathy, critical creativity, mutual care and commitment and ecological entanglement. Together these values form the heart of Hybrid Learning Spaces from which new breeds of teaching and learning are fostered through hybrid forms of becoming, being and the capabilities to be together in, with and for the world. Teaching and learning in hybrid ways changes the thinking, doing, and being, unfolding in the learning space and makes it open up towards the world, fostering a sensitivity towards a value-based conception of learning spaces.

Like Stommel (2012), we see hybrid pedagogy as a methodological approach for processes and practices that are interlinked. The design principles are one way to structure the practices and processes in a Hybrid Learning Space. There is no hierarchy between the principles, they are in constant dialogue with each other and the world.

\section{Conclusion}

This article has explored the characteristics of Hybrid Learning Spaces and their pedagogy. It suggested five general design principles for developing and designing Hybrid Learning Spaces. Hybrid pedagogy means mixing different parts to create something new and it includes different spaces, platforms, people, and resources to do so. Hybridity celebrates and values dialogues between people in different kinds of physical and digital networks and contexts that support hybrid or fluid forms of becoming and being in, with and for the world. The suggested design principles scaffold and promote Hybrid Learning Spaces as intentional and reflective educational practice in higher education; 1) rhizomatic places and knowledge forms, 2) dissolving dichotomies in education, 3) creating a niche in the environment, 4) breadth and depth of the collective and 5) value-sensitive spaces. The design principles are in constant dialogue with each other and with the surrounding contexts.

When teaching and learning take place in Hybrid Learning Spaces as described in this article, higher education has the potential of inviting the students to learn in the world, with the 
world and for the world in a way that cuts across traditional dichotomies and barriers. In order for this to happen, it is necessary that teachers and educational developers take on the challenge of becoming hybrid in their thinking and practice as well as undertake the pedagogical responsibilities that come with these new breeds. Participants in the Hybrid Learning Space need to work together and be there with and for their fellow participants to scaffold and sustain connectivity and belonging in networks as they work together by combining the digital and analogue, online and offline, process and product, university and world, synchronous and asynchronous, formal and informal dimensions of the shared learning space. And importantly, this goes for both teachers and students - although teachers should be able to maintain a general overview. Here, Hybrid Learning Spaces could be a potent educational framework and teaching practice for supporting students in navigating and working past these traditional dichotomies. Through working intentionally to dissolve the dichotomies by fusing them into new formats and practices, teaching and learning, teacher and student are also transformed in the process.

The concept of Hybrid Learning Spaces has the potential to mark an emergence of a higher education practice where its members - students, teachers, scholars, citizens, employees alike - participate together in, for and with society. This article's contribution to the field of learning spaces calls for further research, thinking and practice into the ways higher education institutions and society can work together through forming hybrid partnerships, collectives and spaces to learn together through communication, collaboration, co-creation and citizenship in, with and for the world. This article marks some first steps in taking Hybrid Learning Spaces seriously through theory, development, and practice, a next step would be the formulation of a framework for supporting the teacher in her or his intentional and reflective creation of particular Hybrid Learning Spaces scaffolding and promoting particular pedagogical aims and particular learning interactions and experiences.

\section{References}

Aaen, J. H. \& Nørgård, R. T. (2015). Participatory academic communities: a transdisciplinary perspective on participation in education beyond the institution. Conjunctions: transdisciplinary journal of cultural participation, 2 (2), 1. doi: https://doi.org/10.7146/tjcp.v2i2.22920

Akkerman, S. F. \& Van Eijck, M. (2013). Re-theorising the student dialogically across and between the boundaries of multiple communities. British Educational Research Journal, 39 (1), 60-72. doi: http://dx.doi.org/10.1080/01411926.2011.613454

Bakhtin, M. M. (1984). Problems of Dostoevsky's Poetics (C. Emerson, Trans. C. Emerson Ed.). Minneapolis, MN: University of Minnesota Press.

Barnett, R. (2018). The ecological university. A feasible utopia. New York: Routledge.

Barnett, R. (2011). Being a university. New York: Routledge.

Bates, T. A. W. (2005). Technology, E-learning and Distance Education. Second edition. Oxon: Routledge.

Baym, N. K. (2007). The new shape of online community: The example of Swedish independent music fandom. First Monday, 12, 1-1.

Beldarrain, Y. (2006). Distance Education Trends: Integrating new technologies to foster student interaction and collaboration. Distance Education, 139-153. 
Bengtsen, S. S. \& Nørgård, R. T. (2018). Didaktiske implikationer og principper ved global online inter-universitetsundervisning og hotseat tutorials. Kognition \& Poedagogik, 28 (108), 68-83.

Bhabha, H.K. (1994). The Location of Culture. New York: Routledge

Bligh, B. \& Pearshouse, I. (2011). Doing learning space evaluations. In A. Boddington \& J. Boys (Eds.), Re-shaping learning: A critical reader: The future of learning spaces in post-compulsory education (pp. 3-18). Rotterdam: Sense Publishers.

Bucher, T. \& Helmond, A. (2017). The affordances of social media platforms. In J. Burgess, A. Marwick \& T. Poell (Eds.), The SAGE Handbook of Social Media (pp. 223-253). London: SAGE Publications Ltd.

Canals, L., Burkle, M. \& Nørgård, R. T. (2018). Universities of the future: several perspectives on the future of higher education. International Journal of Educational Technology in Higher Education, 15 (46).

Dabbagh, N. \& Kitsantas, A. (2012). Personal Learning Environments, social media, and selfregulated learning: A natural formula for connecting formal and informal learning. The Internet and Higher Education, 15 (1), 3-8.

Garrison, D. R. \& Vaughan, N. D. (2008). Blended learning in higher education: Framework, principles, and guidelines. John Wiley \& Sons.

Gibson, J. J. (2014). The Ecological Approach to Visual Perception: Classic Edition. Psychology Press.

Goodyear, P. \& Carvalho, L. (2014). Introduction. In L. Carvalho \& P. Goodyear (Eds.), The Architecture of Productive Learning Networks (pp. 3-22). New York: Routledge.

Goodyear, P. \& Yang, D. F. (2009). Patterns and Pattern Languages in Educational Design. In L. Lockyear, S. Bennett, S. Agostinho \& B. Harper (Eds.), Handbook of Research on Learning Design and Learning Objects: Issues, Applications, and Technologies (pp. 167-187). IGI Global.

Gotved, S. (1997). Det virtuelle fællesskab - om en nyhedsgruppe på Internet. MedieKultur, 27: Internet.

Harasim, L. (2012). Learning Theory and Online Technologies. New York: Routledge.

Harrison, M. (2018). Space as a tool for analysis: Examining digital learning spaces. Open Praxis, 10 (1), 17-28.

Hrastinski, S. (2008). Asynchronous and synchronous e-learning: A Study of asynchronous and synchronous e-learning methods discovered that each supports different purposes. EDUCAUSE Quarterly, 31 (4), 51-55.

Hughes, G. \& Nørgård, R. T. (2017). GO:IT Workshop: Global Online Inter-university Teaching: https://dun-net.dk/nyheder/nyhedsoversigt/goit-workshop-global-online-inter-universityteaching/

Ito, M. (2010). Hanging Out, Messing Around, and Geeking Out: Kids Living and Learning with New Media. MIT Press. 
Jensen, J. L. \& Tække, J. (2018). Sociale medier. Samfundslitteratur.

Jeong, H., Hmelo-Silver, C. E. \& Yu, Y. (2014). An examination of CSCL methodological practices and the influence of theoretical frameworks 2005-2009. International Journal of ComputerSupported Collaborative Learning, 9 (3), 305-334.

Kali, Y., Levin-Peled, R. \& Dori, Y. J. (2009). The role of design-principles in designing courses that promote collaborative learning in higher-education. Computers in Human Behavior, 25 (5), 1067-1078.

Köppe, C., Kohls, C., Pedersen, A. Y., Nørgård, R. T. \& Inventado, P. S. (2018). Hybrid Collaboration Patterns. In: 25th Conference on Pattern Languages of Programs (PLoP), pp. 1-14. ACM International Conference Proceeding Series.

Köppe, C., Nørgård, R. T. \& Pedersen, A. Y. (2018). Towards a pattern language for hybrid education. Proceedings of the VikingPLoP 2017 Conference, 1-18. doi:

https://doi.org/10.1145/3158491.3158504

Livingstone, S. (2012). Critical reflections on the benefits of ICT in education. Oxford Review of Education, 38 (1), 9-24.

Macdonald, J. (2003). Assessing online collaborative learning: process and product. Computers \& Education, 40, 377-391.

Melhuish, C. (2011). What Matters About Space for Learning: Exploring Perceptions and Experiences. In A. Boddington \& J. Boys (Eds.). Re-shaping learning: A critical reader:

The future of learning spaces in post-compulsory education (pp. 81-92). Rotterdam: Sense Publishers.

Moore, M. G. (2013). The Theory of Transactional Distance. In M. G. Moore (Ed.), Handbook of Distance Education. Third Edition. (pp. 66-85). New York: Routledge.

Nørgård, R. T., Mor, Y. \& Bengtsen, S. S. (2019). Networked learning in, for, and with the world. In: Networked Professional Learning: Emerging and Equitable Discourses for Professional Development (p. 71-88). Springer. Research in Networked Learning. doi: https://doi.org/10.1007/978-3-030-18030-0 5

Nørgård, R. T. \& Mathiesen, K. H. (2018). Undervisningsbaserede forskerkollektiver: Fra studenterundervisning til akademiske partnerskaber. Dansk Universitetspoedagogisk Tidsskrift, 13 (24), 82-103.

Nørgård, R. T. \& Bengtsen, S. S. (2016). Academic citizenship beyond the campus: a call for the placeful university. Higher Education Research and Development, 35 (1), 4-16. doi: https://doi.org/10.1080/07294360.2015.1131669

Oliver, M. (2015). From openness to permeability: reframing open education in terms of positive liberty in the enactment of academic practices. Learning, Media and Technology, 40 (3), 365-384. doi: https://doi.org/10.1080/17439884.2015.1029940

Pedersen, A. Y., Nørgård, R. T. \& Köppe, C. (2018). Patterns of inclusion: fostering digital citizenship through hybrid education. Educational Technology \& Society, 21 (1), 225-236.

Rheingold, H. (1993). The virtual community: homesteading on the electronic frontier. Reading, Mass.: Addison-Wesley Pub. Co. 
Rorabaugh, P. \& Stommel, J. (2012). Hybridity, pt. 3: What Does Hybrid Pedagogy Do? Hybrid Pedagogy. Retrieved from: http://www.digitalpedagogylab.com/hybridped/hybridity-pt-3what-does-hybrid-pedagogy-do/

Salmon, G. (2011). E-moderating. The Key to Teaching and Learning Online. New York:

Routledge.

Stommel, J. (2012) Hybridity part 2, what is hybrid pedagogy? Hybrid Pedagogy. Retrieved from: http://www.digitalpedagogylab.com/hybridped/hybridity-pt-2-what-is-hybridpedagogy/

Temple, P. (2008). Learning spaces in higher education: an under-researched topic. London Review of Education, 6 (3), 229-241.

Wang, Q. (2009). Design and evaluation of a collaborative learning environment. Computers \& Education, 53 (4), 1138-1146. 